\title{
Los comienzos de nuestro Olimpo. Los deportistas como nuevas figuras públicas en Chile en las primeras décadas del siglo $\mathrm{XX}^{*}$
}

\author{
Eduardo SANTA CRUZ ${ }^{* *}$
}

En los años '90 del siglo XIX se inicia el proceso de apropiación del deporte en nuestro país, y con ello de su masificación. A la cabeza de este proceso marchaba el fútbol, seguido por el boxeo y en menor medida por el ciclismo y el atletismo. Con respecto al primero, ya en 1905, El Mercurio consignaba que "...El foot ball ha tomado un incremento colosal, principalmente en la clase obrera. Todos los círculos y sociedades obreras cuentan con uno o varios teams que practican regularmente, tarde y mañana, los días festivos. Otros, los más entendidos en el juego, han fundado algunos clubs que al mismo tiempo de servir de centros de sport, son sociedades de socorros mutuos y de reunión. En éstos reina una armonía y compañerismo en extremo envidiables"1. El proceso apropiatorio no se reduce ni se agota en el hecho reseñado de incorporarse al juego y generar formas de organización y sociabilidad alrededor de él. Hay otro aspecto, tal vez más profundo, ya que habría de significar una alteración del contenido y sentido de la práctica deportiva y que lo relaciona directa y estructuralmente con el carácter de pasión colectiva que rápidamente asumirá aquella. Nos referimos al hecho de que en el deporte practicado por sectores populares adquieren una importancia relevante dos aspectos:

1.- la competencia, es decir, el juego comienza a cobrar sentido en la búsqueda del triunfo, más que en el puro hecho de practicarlo. No sólo será importante competir, sino también ganar.

2.- junto a lo anterior, la importancia de practicarlo hábilmente, virtuosamente, buscando un lucimiento individual y colectivo.

La intuición es que ello está conectado en términos simbólicos con la construcción o refuerzo de ciertas identidades, de reconocimiento y del logro de un espacio o sitio en la sociedad. El triunfo o la derrota; el lucimiento o el fracaso, vienen a ser elementos simbólicamente compensatorios o confirmantes de subordinaciones, frustraciones $\mathrm{o}$ resentimientos, sociales, locales o nacionales. La aparición de la competencia constituyó un salto cualitativo. El hecho de enfrentarse y vencer, tras la gloria del título de campeón, va a movilizar hinchas y simpatizantes de manera masiva. Destacarse, obtener triunfos y títulos, asombrar con un juego espectacular o emocionar con una hazaña deportiva, serán formas de ir acumulando un capital de popularidad y afecto. Al decir de Archetti: "El deporte pasa a ser así un espejo en donde verse y ser visto al mismo tiempo. Estar entre los primeros importará pero, paralelamente, aparecer como el representante de 'algo diferente' será un factor importante de desigualdad. La globalización temprana del deporte no debe verse como un proceso necesario de homogeneización, sino como un espacio en donde producir imaginarios, símbolos y héroes que establezcan discontinuidades. Las reglas universales y

\footnotetext{
* El presente artículo es producto del Proyecto Fondecyt No 1040150.

** Académico e investigador del Instituto de la Comunicación e Imagen. Universidad de Chile.

${ }^{1}$ Diario El Mercurio. Chile. 5 de junio de 1905.
} 
las prácticas son uniformes pero los resultados impulsan no solo las diferencias sino el pensarlas como tales"2.

La hipótesis a trabajar es que la apropiación popular del deporte estuvo relacionada con procesos de construcción de identidades, de afirmaciones y referentes simbólicos nacionales, regionales, clasistas, etc. Sin embargo, ello no debe entenderse como la reivindicación de una total autonomía u originalidad en el desarrollo de la actividad deportiva en nuestros países. Justamente, en el propio carácter del deporte originado en Inglaterra existe un núcleo básico que remite a la cultura moderna en general, en el sentido de la noción de cultura-mundo que plantea Ortiz ${ }^{3}$. En palabras de Elías: “...Puede decirse que cada deporte tiene una fisonomía propia. Cada uno atrae a gente con determinados rasgos de personalidad. Y ello es posible porque goza de una relativa autonomía no sólo respecto a los individuos que lo practican en un momento dado sino también respecto a la sociedad en que se desarrolló. Por ese motivo, algunos deportes desarrollados primero como tales en Inglaterra pudieron ser transferidos y adoptados por otras sociedades como si fuesen propios"4. Dicha autonomía, sigue diciendo el autor, se fue logrando en la medida en que se desarrollaron instancias organizativas superiores dotadas de poder y legitimidad para regular, supervisar y normar las prácticas deportivas, que de este modo dejaron de ser puramente recreaciones espontáneas.

\section{Los primeros deportistas: figuras arquetípicas}

Viviendo el deporte en tanto que ritual cargado de simbolismos, que atañen a los factores estructurales más profundos de la constitución de una cultura, es explicable que el ídolo sea un ser especial, que puede ser visto como el adalid que defenderá nuestro honor, historia y orgullo colectivo y/o aquel que ha llegado donde todos quisiéramos estar. La identificación con el ídolo es tan profunda, estimula estructuras colectivas e individuales tan decisivas que va mucho más allá de una simple consideración racional. Sólo entendiendo el complejo proceso que ha puesto en marcha sobre todo el fútbol sobre un imaginario colectivo que va construyéndose, a partir de una relación por lo menos difícil con su entorno directo y lejano, intentando mantener o readecuar identidades y sentimientos comunes, ante un mundo muchas veces distante o amenazante, es que se logrará aprehender el rol y papel de ese deporte, los clubes y los ídolos en la cultura popular y masiva.

El ídolo deportivo exhibe una diferencia básica con los ídolos provenientes de la música, el cine o el teatro y ella dice relación con que el deportista asume las condiciones del héroe mítico, debido al carácter agonístico de lucha, de triunfo y derrota que es propio del universo de los deportes. El éxito de uno depende del fracaso de otro. Por ello, solo los ídolos deportivos pueden llegar a ser héroes, más aún si esa lucha muchas veces se da en términos de representación de una colectividad nacional, regional o clasista: “...Los deportistas, desde su etapa inicial de agrupación espontánea y autosuficiente, buscaron también un mayor reconocimiento de parte de la sociedad. Así, la actividad fue ganando un espacio mental a

\footnotetext{
${ }^{2}$ ARCHETTI, Eduardo. El potrero, la pista y el ring. Las patrias del deporte argentino. Pág. 14. Fondo Cultura Económica. Buenos Aires. Primera edición, 2001.

${ }^{3}$ ORTIZ, Renato. Mundialización y Cultura. Alianza Editorial. Madrid. 1997. Con esta noción, el autor apunta a la compleja articulación que se plantea entre una dimensión universalista de la cultura moderna, propia si se quiere del carácter de la época, con una dimensión particular que dice relación con la lógica de desarrollo de los procesos modernizadores en cada sociedad y en cada momento histórico.

${ }^{4}$ ELÍAS, Norbert y DUNNING, Eric. Deporte y ocio en el proceso de civilización. Pág. 54. Fondo Cultura Económica. México. Primera edición, 1992
} 
través de un historial de triunfos y fracasos, acompañado de valoraciones nacionalistas que aportaron identificación y acercamiento a su quehacer" 5 .

La aparición de los primeros ídolos deportivos en el caso chileno tomaría un par de décadas y sería la culminación de un proceso en que cohabitarían dos figuras públicas arquetípicas, el original sportsmen, de origen inglés o aristocrático, que jugaría un papel muy importante en la difusión de la actividad, en crear las primeras organizaciones y en educar en sus técnicas y normativas y, por otra parte, el deportista criollo, de origen social mesocrático o popular, quien adaptando algunos de los valores ligados a la concepción del deporte de los anteriores, le imprimiría un sello, como se ha señalado, más cercano a los procesos constitutivos de identidad, de referentes nacionalistas o de instrumento para la educación masiva, en el sentido amplio, y que terminaría predominando y constituyendo el terreno propicio para el surgimiento de figuras amplia y nacionalmente reconocidas durante los años '20, especialmente, y cuyo recuerdo y estimación en el imaginario colectivo ha permanecido por décadas.

Las prácticas deportivas se verificaron primero al interior de la sociabilidad cotidiana de la colonia inglesa y de los colegios o empresas de su entorno más inmediato, lo que significó que se incorporaran rápidamente jóvenes aristócratas criollos. En esos marcos se trataba de reproducir lo más fielmente posible el espíritu deportivo inglés y con ello de una suerte de actitud de vida, propia del perfil de lo que se llamaba un sportsmen. En la concepción citada de Elías, esto se basaba en el convencimiento de que "...la supervivencia y el éxito social dependen hasta cierto punto de una coraza segura, ni demasiado fuerte ni demasiado débil, de autocontrol individual. Hay un marco reducido para la exhibición de los sentimientos fuertes, las antipatías profundas, mucho menos para la ira, el odio mortal o los impulsos violentos" $"$. Esta es la base de lo que se denominó el fair play, como una forma no solo de practicar el deporte, sino casi como una forma de vida, que quería así expresar el grado de civilización alcanzado individual y colectivamente.

En ese marco, es posible entender lo afirmado por uno de los propulsores del deporte y el fútbol en Chile, José A. Alfonso (filántropo, jurista, ministro y dirigente deportivo), quien señalaba que "...Entre los tres grados de educación, es ésta, la educación física, la única que tiene trascendencias jenerales: obra no solamente en su orden propio, sino también en el orden moral i en el orden intelectual"7. Más adelante, argumenta en favor de implantar y difundir masivamente los "juegos ingleses": “...Se cree aquí por muchos que la educación física a la inglesa es una exajeración vituperable (...) ¿Quién podría negar que las cualidades de iniciativa i de empuje de aquella raza admirable no se han desarrollado ahí, en los campos de sport de las escuelas inglesas? (...) Nuestros juegos nacionales nada valen en comparación de los clásicos juegos ingleses, 'football', 'cricket' etc. Están estos últimos admirablemente dispuestos para que, mediante ellos, surjan lozanas en los jóvenes no solamente condiciones de virilidad física, sino también cualidades morales inapreciables" ${ }^{\prime 8}$. Finalmente, dentro de los

\footnotetext{
5 MODIANO, Pilar. Historia del Deporte chileno. Orígenes y transformaciones 1850-1950. Pág. 113. Digeder. Santiago. 1997.

${ }^{6}$ ELÍAS, Norbert y DUNNING, Eric. Op. Cit.

${ }^{7}$ ALFONSO, José A. (Prefacio a) Foot-Ball. Reglas del juego fijadas por la Asociación de la Gran Bretaña y consejos para los jugadores. Traducción de J. D. Sieveking. Editado por Hume y Cía., Imprenta Moderna. Santiago. 1901.

${ }^{8}$ Ibídem.
} 
deportes que considera deben ser asimilados, el fútbol es "...acaso el más interesante de los juegos ingleses i el que con más éxito podría implantarse en Chile"”.

De este modo, los primeros clubes y asociaciones estuvieron organizados por estos sportsmen, en los que cabe destacar, al menos, dos características importantes para el futuro desarrollo de la actividad. Por una parte, especialmente en los casos del fútbol, boxeo y atletismo sus desarrollos en espacios públicos estuvieron acompañados de prácticas no excluyentes, sino que por el contrario, inclusivas y difusoras. De este modo, hay varias figuras de dichos sportsmen que se dedicaron a organizar clubes, a enseñar las reglas y técnicas necesarias, etc. Entre ellos se puede mencionar al llamado "padre del fútbol santiaguino", Juan Ramsay: “...Tranquilo de temperamento, de gran entusiasmo i deseoso de ver siempre que las instituciones llevaran una marcha ascendente, sobre todo las obreras, ha puesto al servicio de esta nobilísima idea todos sus conocimientos, siendo instructor, árbitro i uno de los backs de juego más limpio i brillante que han actuado en los fields" ${ }^{\text {. }}$. La reseña que la publicación citada hace de su personalidad y aporte culmina con un juicio que sintetiza lo antes planteado, al anotar que "...en toda ocasión ha demostrado ser un verdadero gentleman, chileno de nacimiento i de corazón, pero inglés en todos los actos de su gloriosa vida deportiva" ${ }^{\prime 1}$. Por otro lado, en términos generales, el hecho de que ciertos deportes se masificaran y popularizaran rápidamente no significó que los miembros de la elite se marginaran, sino que más bien trataron de orientar y dotar a esta nueva realidad de un cuerpo valórico acorde, en alguna medida, con el espíritu original. Ayudó a ello la incorporación de los deportes al proyecto de masificación de la educación formal, con fuerte presencia estatal. En conjunto, en el caso chileno se creó así una mixtura que amalgamó una visión del deporte compatible con una versión masiva, popular y criolla del fair play inglés. De esa mezcla surgió el deportista criollo y, luego, el ídolo deportivo. La misma proliferación de la actividad, su práctica realizada en espacios públicos, el hecho de que comenzara a ser registrada en los periódicos y, no menos importante, el hecho de que sus cultores miembros de la colonia británica o la aristocracia criolla se preocuparan por difundirla y hacerla conocida, provocó que fuera imposible, y muchas veces no deseable, que el deporte se mantuviera circunscrito a círculos estrechos.

Dicho proceso que abarcó las dos primeras décadas del siglo XX no estuvo, sin embargo, exento de tensiones y conflictos. Uno de los puntos principales de roce entre ambas concepciones y arquetipos deportivos lo constituyó la incipiente profesionalización de la actividad. El tema estuvo desde el inicio planteado en dos ámbitos: por un lado, en lo que se refiere a la obtención de premios o estímulos que significaran un reconocimiento social y público de los triunfos y que se materializó en medallas, trofeos, diplomas, etc. y, por otro lado, en la obtención de incentivos o estímulos monetarios que permitieran especialmente a los jóvenes provenientes de sectores populares una dedicación más completa a la preparación y el entrenamiento. Dicho directamente, en una época en que existía una escasa reglamentación estatal sobre las jornadas y condiciones de trabajo, la dedicación de mucho tiempo a las prácticas del sport aparecía como un lujo que solo se podían permitir los que tenían suficientes recursos económicos para ello. El pago, durante mucho tiempo solapado y subrepticio, a ciertos deportistas venía a compensar la pérdida de ingresos por días no trabajados. Dicho brevemente, el profesionalismo se instaló como una tendencia creciente y paulatinamente

\footnotetext{
${ }^{9}$ Ibídem.

${ }^{10}$ Revista Sport i Actualidades. Chile. № 8.16 de junio de 1912.

${ }^{11}$ Ibídem.
} 
irresistible, a pesar de las resistencias y los ataques, porque al cubrir necesidades económicas ampliaba el acceso y democratizaba la práctica de los deportes y, además, porque cubría también el ya mencionado reconocimiento simbólico, cuestión central en el proceso de apropiación popular y masiva del deporte ${ }^{12}$.

Sin embargo, la consecución de un cierto equilibrio entre la democratización por esta vía y el respeto al espíritu deportivo original no fue fácil. En un comienzo, los sportsmen fundadores e incluso la naciente prensa deportiva atacó frontalmente tanto la compensación monetaria como los premios simbólicos, en tanto objetivos de la práctica del deporte. Así, El Diario Ilustrado acerca de las características de los llamados old boys, señalaba que “...En su tiempo no se jugaba por premios como ahora que nadie juega por amor al ejercicio y la vida al aire libre. La juventud que introdujo los deportes en Chile practicaba los juegos por convencimiento de sus bondades, con verdadera pasión y entusiasmo" ${ }^{\text {". }}$. Más fuertes aún eran los juicios de una revista que afirmaba: “...Queremos el sport para los sportsmen y no para los que medran a su costa... Combatiremos la conquista de jugadores en el foot ball; el profesionalismo irritante" ${ }^{14}$. Del mismo modo, criticaba, “...el afán que tienen todos los footballers, tanto de parte de los recién iniciados como de aquellos que pueden considerarse campeones, de lucirse, es decir, de practicar el deporte con el fin de hacerse aplaudir y conquistar renombre" ${ }^{, 15}$. La polémica mencionada se centró en la época fundamentalmente en el fútbol y tendría un hito importante en la década de los '20 con la fundación de Colo-Colo, por la acción de David Arellano y sus hermanos, profesores primarios de origen modesto, propulsores y propagandistas de la modernización del fútbol, vía profesionalismo ${ }^{16}$.

\section{El héroe deportivo en Chile: sus orígenes}

Desde el comienzo aparecieron figuras que por distintas razones fueron destacándose y concitando algún grado de estimación y admiración pública, cuestión facilitada por la atención creciente dada por los diarios a la actividad, así como por la aparición de las primeras revistas especializadas. Sin embargo, hasta 1920 más o menos, todavía la resonancia de los logros y hazañas de estas primeras figuras del deporte nacional solamente llegaba poco más allá del círculo propio de su quehacer.

Entre ellos cabe mencionar, de modo puramente ilustrativo, a Carlos Hormazábal ${ }^{17}$ y Próspero González ${ }^{18}$, en fútbol; a Juan Jorquera ${ }^{19}$ y Rodolfo Hammersley ${ }^{20}$, en atletismo;

\footnotetext{
${ }^{12}$ SANTA CRUZ, Eduardo y SANTA CRUZ, Luis. Las escuelas de la identidad. La cultura y el deporte en el Chile desarrollista. Págs. 165 y ss. Ediciones Arcis-LOM. Santiago. Primera edición, 2005.

${ }^{13}$ El Diario Ilustrado. Chile. 25 de noviembre de 1911.

${ }^{14}$ Revista Sport i Actualidades. Chile. N ${ }^{\circ} 10.30$ de junio de 1912.

${ }^{15}$ Revista Sport i Actualidades. Chile. $N^{\circ} 94.8$ de febrero de 1914.

${ }^{16}$ SALINAS, Sebastián. Por empuje y coraje. Los albos en la época amateur, 1925-1933. CEDEP. Santiago. 2004.

${ }^{17}$ Carlos Hormazábal, nació hacia 1885. Profesor primario, titulado en la Escuela Normal José A. Núñez y, por tanto, jugador de Magallanes. Capitán de las primeras selecciones nacionales, que compitieron en el Torneo del Centenario en Argentina, en 1910 y en la gira a Brasil en 1913: "...gran figura de las canchas santiaguinas de comienzos de siglo. Prolongaría largamente su carrera en su club y, más tarde, en las selecciones nacionales que en sus comienzos se conformaban mayoritariamente con jugadores ingleses. Fue, en rigor, el primer crack del fútbol chileno" (MARÍN, Edgardo. Historia total del fútbol chileno. Pág.40. Editores REI. Santiago. 1995.)

${ }^{18}$ Próspero González, nació hacia 1884. Fundador del Arco Iris FC, club obrero de la capital, donde jugó cerca de 20 años. También practicó atletismo. Fue Seleccionado nacional en fútbol: "...modesto obrero, le ofrecieron empleos más cómodos y mejor renta para que dejara su 'Arco Iris', pero prefirió continuar en su elenco pobre" (Revista Estadio. Chile. $\mathrm{N}^{\circ}$ 175. 21 de septiembre de 1946).
} 
Heriberto Rojas ${ }^{21}$ y Manuel Sánchez ${ }^{22}$, en boxeo o los hermanos Torralva, en tenis ${ }^{23}$. Como se puede ver en estos casos, las competencias internacionales comenzaron en distintos deportes en la década de los '10. Como señalamos antes, aquellas constituyeron situaciones en que se movilizaban importantes contenidos identitarios, esta vez a escala nacional; de esa manera, esos primeros logros ubicaron las contiendas deportivas como lugares especialmente relevantes para la reafirmación simbólica colectiva y no es menos importante que, salvo los hermanos Torralva, todos los nombrados pertenecieran a sectores sociales medios o populares. Las actuaciones internacionales fueron las que provocaron la irrupción entusiasta del deporte y sus héroes en espacios públicos más amplios. Como muestra algunos casos: en septiembre de 1913 y por invitación del gobierno brasileño, viajó por barco, vía Estrecho de Magallanes, la Selección Nacional de Fútbol a jugar una serie de encuentros en ese país. Debido a los conflictos entre las organizaciones de Santiago y Valparaíso, esta última se marginó y la Selección estuvo constituida solamente por jugadores de la capital, capitaneados por el citado Hormazábal. En resumen la expedición tuvo auspiciosos resultados: jugó seis partidos, ganando tres, perdiendo solo dos y empatando uno. La prensa nacional fue publicando los pormenores de esta gira que duró más de un mes, de modo que al regreso de los jugadores había una multitud en la Estación Central: "....a la llegada del tren un viva salido de diez mil corazones atronó el aire... se organizó un imponente desfile de todas las sociedades deportivas, colegios y sociedades obreras, pasando por la Embajada de Brasil, donde se hizo una colosal manifestación de aprecio a la nación hermana"24.

En 1917 se llevó a cabo la disputa de la Copa América de Fútbol en Montevideo, con la participación de Argentina, Chile, Brasil y Uruguay y se inauguró la costumbre de que los diarios más importantes de Santiago y Valparaíso colocaran pizarras donde se iban escribiendo el contenido de cables con las noticias de los partidos, a medida que estos transcurrían. Normalmente eran centenares de personas las que seguían los detalles de los encuentros de esta forma. Por otra parte, en 1923 los hermanos Torralva ganaron la Copa Mitre ante Argentina, en Buenos Aires. Esta disputa era entre equipos nacionales, con el formato de la Copa Davis y se celebró durante varias décadas. El triunfo del equipo nacional provocó, según comentarios de prensa, que: “...una sacudida de intenso entusiasmo ha despertado el alma de Chile entero al conocerse la victoria que los adalides del racket conquistaron en las arenas de la metrópoli bonaerense...Tenemos el derecho de escalar los

\footnotetext{
${ }^{19}$ Juan Jorquera, ganó la Maratón del torneo sudamericano celebrado en Buenos Aires en 1918 con un tiempo que superaba el record mundial, aunque la marca no fue oficialmente homologada.

${ }^{20}$ Rodolfo Hammersley, en 1910 participó en un campeonato realizado en Buenos Aires, con ocasión de las fiestas del Centenario, ganando la difícil prueba del Decatlón. Ese mismo año igualó el record mundial de los cien metros planos.

${ }^{21}$ Heriberto Rojas, oriundo de Santa Cruz, Colchagua, llegó a la capital en 1904 para entrar a la Policía. En 1905 tuvo su primera pelea con el profesional norteamericano James Perry, con quien combatió "a finish", es decir sin límite de rounds, hasta que uno quedara K.O. Rojas ganó en el round 17 provocando el delirio del público que al fin tenía un campeón chileno, a quien premió con una lluvia de monedas de un peso, según la citada Pilar Modiano.

${ }^{22}$ Manuel Sánchez, se coronó en 1914 como el primer chileno campeón sudamericano, título que retuvo hasta 1922.

${ }^{23}$ Domingo y Luis Torralva nacieron en 1900 y 1902, respectivamente. Se iniciaron en el tenis en 1916. En 1923 ganaron la Copa Mitre ante Argentina, en Buenos Aires. En 1926 se radicaron en Francia y fueron finalistas en dobles en Roland Garros. En 1928 y 1929 integraron el equipo chileno que participaba por primera vez en Copa Davis, ante España y Dinamarca, respectivamente.

${ }^{24}$ Revista Sport i Actualidades. Chile. N ${ }^{\circ} 78.19$ de octubre de 1913.
} 
peldaños de una figuración destacada en el concierto deportivo mundial...Santiago entero debe trasladarse a la Estación Mapocho con estandartes y faroles chinescos". De hecho, a la llegada del tren trasandino a la Estación de Las Cuevas los esperaba una delegación oficial y conjuntos folclóricos. Más tarde los recibió el Presidente Arturo Alessandri en La Moneda y hubo numerosos banquetes y celebraciones ${ }^{25}$.

Las competencias internacionales y la difusión hecha por la prensa escrita y la radio provocaron en los años '20 la consolidación de ciertas figuras en esta suerte de Olimpo deportivo nacional. Entre ellos, cabe destacar la presencia de Estanislao Loayza, Manuel Plaza y David Arellano ${ }^{26}$. Loayza era un iquiqueño, que se ganaba la vida como matarife cuando el manager Louis Bouey descubrió sus condiciones, llevándolo de inmediato a EE.UU., sin pasar por la capital. Eso ocurrió a fines de 1924 y después de una rápida y exitosa campaña se ganó el derecho de disputar el título mundial contra Jimmy Goodrich. Permaneció en EE.UU. hasta 1929 combatiendo en más de cien peleas. En 1926 fue elegido el mejor peso liviano de Estados Unidos, según una encuesta de popularidad de un diario de Nueva York y su retrato quedó hasta ahora instalado en el Salón de la Fama del Madison Square Garden.

Sin embargo, lo más significativo para su inserción como héroe deportivo nacional, sucedió el 13 de julio de 1925, cuando disputó el título de campeón mundial. Siendo favorito de la prensa iba dominando claramente la pelea, cuando sufrió una lesión al tobillo que provocaría su derrota por puntos. Las crónicas de la prensa de la época hablan de una mala pisada, a raíz del irregular piso de lona del ring. No obstante, el episodio quedaría para siempre como "...un pisotón del árbitro". Fue el primer episodio de una constante a lo largo del siglo XX: la existencia de una suerte de sino fatal, que proviniendo de la casualidad, de la imprevisión o de la acción malintencionada de terceros, afecta a nuestros héroes impidiéndoles el logro de triunfos y títulos, siempre en el último y decisivo momento.

Algo similar ocurrió con Manuel Plaza. Nacido en 1901, ha sido quizás la máxima figura del atletismo nacional. De origen muy modesto, comenzó desde los catorce años a participar en carreras de mediofondo, fondo y maratón. Hacia 1920 ya era un atleta destacado y seleccionado a torneos sudamericanos. En 1924 ganó todas las pruebas antes señaladas en los Juegos Latinoamericanos ${ }^{27}$. En 1928 fue segundo del maratón en los Juegos Olímpicos de

\footnotetext{
${ }^{25}$ MODIANO, Pilar: Op. Cit. Pág. 123

${ }^{26}$ Cabe señalar que el boxeo entregó otros nombres también ampliamente conocidos y populares. Es el caso de Quintín Romero y Luis Vicentini, de destacada actuación en Europa y EE.UU., respectivamente. Incluso, hubo un caso especial, el del argentino Luis Angel Firpo, quien iniciara su carrera en Chile en 1918, lo que le acarreó el cariño de la afición. De hecho, cuando en 1923 llegó a disputar el título mundial con Jack Dempsey, ello provocó una gran expectación e interés en nuestro país y más de dos mil personas llegaron al frontis del diario La Nación, para seguir las alternativas del combate, a través de la información que se iba anotando en sus pizarras: “...estamos frente a un hombre de un porvenir brillante y que será sin duda el campeón del mundo, para gloria de los argentinos, y un poquito...para nosotros los chilenos" (Revista Los Sports. Chile. $\mathrm{N}^{\circ}$ 2. 23 de marzo de 1923). Lamentablemente los deseos no se cumplieron, ya que El Toro Salvaje de las Pampas, como lo llamaba la prensa norteamericana, perdió por K.O. al segundo round.

27 "...Plaza es un atleta completo: une a un cuerpo esbelto y bien formado, una musculatura bien diseñada. Moreno, de ojos vivaces, tranquilo y modesto al hablar de su persona, se impone entre los de su clase...Nació humilde y sigue la vida que empezó desde niño, vendiendo diarios en un puesto que ahora tiene por su cuenta en la calle Bascuñán Guerrero esquina de Blanco Encalada...No hace mucho ha cumplido 22 años de edad y a pesar de su juventud hace cinco años que unió sus destinos a una niña que ha sabido comprenderlo como él esperaba...Tiene una hijita que es el encanto de su hogar...Debido a sus escasos recursos no ha podido nunca seguir un régimen especial de alimentación, como se aconseja a todos los corredores, y riéndose nos diría que comiendo poco cuando no tenía dinero, y más cuando la venta de diarios mejoraba, así sin régimen alguno, debido a su constitución física, ha logrado los triunfos conocidos" (Revista Los Sports. Chile. N $^{\circ} 2.23$ de
} 
Amsterdam, a escasos metros del ganador que terminó desfalleciendo, mientras Plaza, que había arremetido con fuerza, se daba maña para aún dar una vuelta a la pista para recibir el aplauso del público. Nuevamente, la prensa de la época solo habla de una incorrecta planificación de la carrera, que habría provocado que Plaza iniciara tardíamente su ataque decisivo. Sin embargo, la versión que quedó para siempre en el imaginario nacional es que, por falta de recursos, Plaza habría corrido solo sin el apoyo de nadie a su alrededor como es costumbre en esta prueba y, por esto, habría extraviado la ruta por las calles de la ciudad, perdiendo minutos valiosos.

Por su lado, como es sabido, la fatalidad en el caso de David Arellano ${ }^{28}$ culminaría con su muerte en la ciudad española de Valladolid. Profesor primario, nació en 1902 e ingresó a Magallanes en 1919, destacándose rápidamente. Seleccionado nacional, participó en la Copa América de 1924. Encabezó la modernización del fútbol, en tanto espectáculo, junto a sus hermanos y otros jugadores jóvenes de Magallanes, a partir de su salida del club y de la fundación de Colo-Colo. Su popularidad se acrecentó en 1926, a raíz de su participación en la Copa América, realizada en Santiago y donde se proclamó goleador del torneo. Al año siguiente, 1927, promovió y organizó la primera gira de un club chileno a Europa. Como es sabido, horas después de jugar contra el Real Valladolid, Arellano falleció en su alojamiento del hotel. Se dijo que sufría de una hernia y que un golpe sufrido en el partido habría provocado su ruptura; también, que habría sufrido de una apendicitis ignorada u ocultada para no perderse el encuentro, en fin, lo concreto es que sin recibir una atención especializada y en la pieza del hotel, se convirtió de héroe en mártir.

Los casos señalados, además de portadores y víctimas de una fatalidad predestinada, compartieron otros factores que serían luego requisitos para ser postulados al sitial de ídolo o héroe deportivo, además de destacarse en las competencias: su origen social modesto y una vida privada y pública que cupiera en los moldes de un modelo virtuoso, digno de ejemplo y donde los valores deportivos fueran vividos consecuentemente, dentro y fuera de los estadios. Por último, cabe señalar que hay otro rasgo que los une: ser hombres. La historia de los deportes en estas primeras décadas de su desarrollo en nuestros países es una historia eminentemente masculina. La presencia de la mujer es más bien marginal, eventualmente como espectadora de los espectáculos deportivos, en compañía de esposos, hermanos o padres $\mathrm{y}$, como practicante, circunscrita a ciertos deportes que hicieran lucir y en cualquier caso, no menoscabar lo que se consideraba femineidad, desde el punto de vista masculino dominante. Por ello, es que difícilmente encontramos figuras públicas deportivas femeninas en esos primeros años ${ }^{29}$.

Sin embargo, toda regla tiene una excepción. En 1925 hizo su debut oficial como tenista, una joven menuda, de allí su posterior apodo de la Ratita, que en los años '30 llegaría a ser considerada como la mejor tenista del mundo: Anita Lizana, que sería la primera gran heroína femenina del deporte nacional.

\footnotetext{
marzo de 1923).

${ }^{28}$ ARELLANO, Alberto M. David Arellano Moraga, el deportista mártir. Imprenta Atenas. Santiago. 1929 y SALINAS, Sebastián. Op. Cit.

${ }^{29}$ Un par de décadas más tarde, tanto el atletismo como el básquetbol femeninos, ampliamente exitosos a nivel sudamericano, entregarían numerosos casos de deportistas ampliamente reconocidas y queridas por el público, destacándose especialmente las figuras de Marlene Ahrens, medallista olímpica y recordwoman a nivel panamericano, en atletismo e Ismenia Pauchard, basquetbolista.
} 